\title{
PARA QUE SERVE A PESQUISA EM EDUCAÇÃO?
}

\author{
MARIA MALTA CAMPOS \\ Pesquisadora do Departamento de Pesquisas Educacionais da Fundação \\ Carlos Chagas e Professora do Programa de Pós-Graduação em Educação - \\ Currículo, da Pontifícia Universidade Católica de São Paulo \\ mcampos@fcc.org.br
}

\begin{abstract}
RESUMO
Constatada uma crescente insatisfação, por parte de gestores da escola pública diante das pesquisas desenvolvidas na universidade, o artigo analisa as relações entre a pesquisa e as práticas educativas, procurando mostrar as diversas influências cruzadas existentes. Com base nos escritos de Charlot, Rayou, Dubet, Tardife Zourhlal, o texto examina as diferentes formas como os atores sociais incorporam e reinterpretam resultados de pesquisa em suas concepções sobre a educação e, também, como a produção acadêmica é marcada por disputas que se originam na dinâmica social mais ampla. Um comentário crítico específico é feito sobre o movimento em favor de "práticas e políticas baseadas em evidências", tendência que tem prosperado nos meios educacionais de fala inglesa, defendendo um modelo experimental de pesquisa que, baseado em amostras aleatórias, é considerado como o único que poderia oferecer resultados confiáveis para subsidiar políticas públicas de educação. O artigo sugere, em lugar da pergunta "para que serve?", uma indagação a respeito de como circulam conhecimentos e opiniões entre os dois campos. Conclui enfatizando o fato de que a pesquisa é uma atividade humana como as outras, pois a universidade e os centros de pesquisa não estão fora da sociedade. Nesse sentido, o artigo aponta para a potencialidade de um diálogo aberto entre os dois modos de conhecer e agir, aquele da investigação e da reflexão crítica e aquele da ação política e profissional.

PESQUISA EDUCACIONAL - ENSINO SUPERIOR - PRÁTICA DE ENSINO
\end{abstract}

\section{ABSTRACT}

WHAT IS RESEARCH IN EDUCATION FOR? There is a growing dissatisfaction, on the part of public school administrative personnel, with researches that have been developed in the university. This article analyses the relations between the research and the educational practices, trying to show the diverse crossed influences present in them. Based on the writings of Charlot, Rayou, Dubet, Tardif and Zourhlal, the text examines how social actors incorporate and reinterpret through different forms the results of research in their conceptions about education and, also,

Texto de palestra apresentada na abertura do $6^{\circ}$ Colóquio de Pesquisa em Educação, promovido pelo Programa de Pós-Graduação em Educação, da Pontifícia Universidade Católica de Minas Gerais - PUC/MG - em 19 de setembro de 2008. 
how academic research is marked by disputes that arise in the broader dynamic of society. A critical commentary is made about the movement on behalf of "evidence-based policies and practices", tendency that has prospered among educational English speaking circles, defending an experimental model of research that, based in random samples, is considered as the only one able to offer dependable results for subsidize public education policies. The article suggests that the main question is not "what is research in education for?" which should be replaced by "how knowledge and opinions circulate between these two fields? It concludes emphasizing the fact that research is a human activity as any other, since universities and centres of research are part of the society. In that sense, the article points out the potential of an open dialogue between two ways of know and act: that of the inquiry and critical reflection and that of the professional and political action.

EDUCATIONAL RESEARCH - HIGHER EDUCATION - EDUCATIONAL PRACTICE

Há alguns meses, os leitores de uma revista de circulação nacional foram surpreendidos por declarações da Secretária de Estado de Educação de São Paulo que culpava as faculdades de pedagogia, inclusive aquelas das duas mais prestigiosas universidades do estado, a Universidade de São Paulo - USP - e a Universidade Estadual de Campinas - Unicamp -, pelos sérios problemas do ensino público, sugerindo que essas instituições deveriam ser fechadas, para o bem geral das escolas paulistas'.

Essa reação é interessante, pois até esse momento as críticas à formação de educadores oferecida pelas universidades e à sua produção acadêmica apontavam o distanciamento em relação aos problemas reais vividos pelas escolas ou sua falta de compromisso com a melhoria do ensino, mas não chegavam a afirmar que esse ensino e essa produção fossem totalmente prejudiciais aos futuros professores e à educação pública. Parece, assim, que a percepção de um fosso que estaria separando a universidade do mundo real das escolas evoluiu na direção de uma suspeita de que a universidade estaria, sim, atingindo as escolas, porém de uma forma bastante negativa.

Para abordar essa polêmica, seria preciso primeiro recuperar a trajetória recente da pesquisa educacional, para em seguida rediscutir as relações

I. Suas palavras foram: "Num mundo ideal, eu fecharia todas as faculdades de pedagogia do país, até mesmo as mais conceituadas, como a da USP e a da Unicamp, e recomeçaria tudo do zero. Isso porque se consagrou no Brasil um tipo de curso de Pedagogia voltado para assuntos exclusivamente teóricos, sem nenhuma conexão com as escolas públicas e suas reais demandas" (Castro, 2008). 
entre a pesquisa e as práticas educativas, buscando obter alguma distância crítica entre posições extremadas, é bom que se diga, em ambos os campos: o da política e o da pesquisa acadêmica.

\section{A PESQUISA EM EDUCAÇÃO DIVIDIDA ENTRE DOIS CAMPOS}

Em outro trabalho, eu havia observado como a pesquisa em educação caminhou, nos últimos anos, em direção a uma cisão entre dois campos de produção paralelos: o campo acadêmico, formado principalmente pela produção no contexto dos programas de pós-graduação das universidades e um outro campo, situado em instituições com certa autonomia em relação ao primeiro, como, por exemplo, as instituições independentes de pesquisa, as organizações não governamentais e os institutos empresariais, associados ou não a órgãos oficiais nacionais. Nessa análise, eu havia comentado que esses dois campos apresentam muitas diferenças, não só nas condições que oferecem para a realização de pesquisas, mas também no tipo de relacionamento que estabelecem com os gestores de políticas educacionais e, em alguns casos, com os organismos internacionais que atuam no financiamento dessas políticas (Campos, 2006).

Na raiz da importância crescente dessas outras fontes de produção de pesquisa sobre educação, é possível identificar certa frustração com a pesquisa acadêmica, julgada, por aqueles que precisam tomar decisões sobre política educacional, como pouco objetiva, fragmentada e distanciada dos problemas educacionais considerados mais urgentes. Financiamentos substantivos foram assim dirigidos a instituições com perfil mais pragmático, que oferecessem competência adquirida para lidar com o grande volume de dados quantitativos colhidos pelos sistemas de avaliação centralizados, criados na década de noventa, ou que tivessem condições de colher dados novos a partir de amostras representativas de universos amplos, oferecendo resultados objetivos a curto prazo, na maior parte das vezes de acordo com encomendas definidas externamente às equipes de pesquisa.

Enquanto isso, os grupos de pesquisa acadêmicos prosseguiram em sua trajetória com bastante autonomia, focalizando os problemas da educação segundo suas orientações teóricas e ideológicas, utilizando em menor ou maior grau, conforme os perfis de cada grupo, dados empíricos colhidos em pequena 
escala, geralmente de cunho qualitativo. Essa produção, ao contrário do que acontece com a outra, vem sendo objeto de muitos balanços críticos ${ }^{2}$, que têm apontado suas principais limitações e contradições.

Como mostrei naquele artigo, uma síntese de diagnósticos relatada por Whitty, sobre pesquisas realizadas no Reino Unido, destaca críticas semelhantes: "falta de rigor; falha em produzir resultados de pesquisa cumulativos; incoerência teórica; viés ideológico; irrelevância para as escolas; falta de envolvimento dos professores; inacessibilidade e pouca disseminação; baixa relação custobenefício" (Campos, 2006, p.48).

Note-se que muitas dessas críticas aplicam-se indistintamente aos dois campos mencionados, sendo que o campo acadêmico tem sido submetido a esse tipo de avaliação de forma muito mais sistemática que o outro.

\section{A REALIDADE EDUCACIONAL EM TEMPOS DE REFORMA}

Sobre que realidade essas pesquisas vêm sendo produzidas? Uma primeira dificuldade para responder a essa indagação resulta do fato de que, no país, enfrentamos, lado a lado, problemas de eras passadas, como o analfabetismo e a falta de acesso ao ensino, e problemas contemporâneos, comuns às nações ocidentais mais desenvolvidas, como, por exemplo, a demanda por reconhecimento das diversidades étnicas e culturais, a necessidade de garantir aos alunos a aquisição de competências múltiplas e flexíveis e não só o domínio de conteúdos disciplinares tradicionais, a reivindicação por ações afirmativas, que vão além das exigências por igualdade, entre muitos outros aspectos.

A crise da educação é um fenômeno identificado nos países desenvolvidos e não só entre nós. Está intimamente ligada ao desemprego estrutural, ao estancamento das oportunidades de ascensão social via maior escolaridade, ao esvaziamento dos canais de participação política e à crise dos Estados nacionais no contexto da globalização da economia ${ }^{3}$.

2. Ver os Estados do Conhecimento publicados pelo Instituto Nacional de Estudos e Pesquisas Educacionais -Inep -, realizados em conjunto com a Associação Nacional de Pós-Graduação e Pesquisa em Educação - Anped - e os diversos balanços apresentados nos Grupos de Trabalho da Anped sobre a produção dos grupos ao longo de suas respectivas trajetórias.

3. Ver apresentação ao dossiê Penser la crise de l'école, publicado pela Revue du Mauss (Caillé, 2006). 
A esses dados, soma-se o impacto que as recentes reformas educacionais tiveram na sociedade, principalmente a partir dos anos noventa, impondo uma pauta de questões que ganhou grande visibilidade na mídia, atraindo novos atores para o campo educacional, como profissionais de outras áreas, empresários, associações e deixando em segundo plano os atores tradicionais, como os professores e seus sindicatos, os especialistas e os intelectuais da educação. Essas reformas, como muitos já apontaram, foram adotadas a partir de agendas formuladas por organizações internacionais, como a Unesco, o Banco Mundial e a Organização para a Cooperação e Desenvolvimento Econômico - OCDE -, fazendo com que fórmulas comuns fossem aplicadas a realidades nacionais e regionais muito diversas, incentivando a comparação internacional de indicadores educacionais e aproximando os debates nacionais a uma pauta comum.

Uma segunda dificuldade encontra-se no fato de que a sociedade contemporânea absorve, em sua própria realidade e na consciência de seus atores, elementos com origem nos campos de produção intelectual, de forma que, como sintetiza Patrick Rayou (2002) em sua apresentação ao dossiê Para que serve a sociologia da educação?, "as fronteiras [...] entre o mundo erudito e o mundo da opinião estão agora embaralhadas”. Citando Giddens, ele diz que "os atores que fazem parte dos objetos das ciências sociais são também teóricos do social", ou seja, apropriam-se, a seu modo, de noções provenientes das ciências sociais. Isso significa que a postura crítica não seria mais uma exclusividade do pensamento sociológico, mas estaria disseminada na sociedade. "A hiper-reflexividade contemporânea não poupa nenhum objeto e a escola menos ainda, tanto esse campo é politicamente sensível" 4 , diz Rayou (p.8). Portanto, nessa perspectiva, não se sustenta uma pergunta do tipo "para que serve", mas no seu lugar teríamos de indagar a respeito da circulação de conhecimentos e opiniões entre pesquisadores e sociedade, abordando dialeticamente as relações entre conhecimento especializado e conhecimento comum (Rayou, 2002, p.7).

Esse fenômeno pode também ser observado em dados colhidos por pesquisas em educação no Brasil, quando professores ou mesmo pais dão respostas aos pesquisadores, reproduzindo ou se inspirando em teorias ou resultados de pesquisas incorporados ao senso comum. Muitas vezes essas

4. As traduções das citações do francês e do inglês são da autora. 
noções se referem a análises já criticadas e superadas no meio acadêmico, mas que ainda provocam adesões de atores sociais implicados na realidade educacional e social. Um exemplo é a teoria da privação cultural, divulgada nos anos sessenta a partir de pesquisas realizadas nos Estados Unidos, que ainda hoje circula amplamente entre professores, como explicação para o fracasso escolar de crianças de classe trabalhadora.

O terceiro tipo de dificuldade diz respeito ao caráter propositivo que a produção sobre educação possui, pois nosso campo é um campo essencialmente voltado a uma prática social na qual, como pesquisadores e intelectuais formadores de educadores, somos também atores. No desenho de muitas dessas propostas educativas estão implicadas posições ideológicas que se entrecruzam com o jogo político partidário e embaralham as fronteiras entre o campo acadêmico e o campo de atuação política. Isso ocorre não só com a participação em cargos de gestão de especialistas da universidade, como também nas posições críticas sobre determinadas opções em política educacional, que por vezes assumem contornos político-partidários, oscilando ao sabor da conjuntura. Assim, em muitos casos, seria preciso inverter a pergunta "para que serve", indagando a academia sobre as influências que sofre a partir da dinâmica social.

Como mostra Charlot - e Bourdieu antes dele -, na formulação dos objetos de pesquisa pode existir a influência de uma agenda externa que se impõe aos pesquisadores na forma de objeto, mas que, por isso mesmo, não seria de fato um objeto de conhecimento construído a partir de paradigmas científicos. "Quando um campo está tão saturado de respostas", diz Charlot, "é difícil levantar questões de maneira nova: portanto é difícil fazer pesquisa." Para esse autor, o campo da educação é um campo "saturado de discursos já instalados, já prontos." A seu ver, a educação seria uma disciplina "epistemologicamente fraca", com dificuldades para recortar seu objeto "na complexidade do real", na qual é difícil escapar dos "objetos sociomidiáticos", aqueles "objetos que a opinião pública e os políticos, e na sua esteira os jornalistas, questionam” (Charlot, 2006, p. I4).

Exemplos de objetos sociomidiáticos são, de acordo com Charlot, "o fracasso escolar, a violência na escola, a cidadania, a parceria educativa, a qualidade da educação, a avaliação, e ainda, sem nunca sair de moda, a formação de professores" (2006, p. I4). Diz o autor: 
Podemos fazer uma pesquisa partindo de temas sociomidiáticos que não são apenas efeito da moda, mas que remetem a problemas sociais fundamentais. Porém isso supõe que se defina, a cada momento, um objeto de pesquisa, pois esses temas não são, e não podem ser, enquanto tais, objetos de pesquisa. (Charlot, 2006, p. I5)

Por tudo isso, vemos que as relações entre a pesquisa e a realidade educacional não são simples, nem unidirecionais, não comportando, portanto, perguntas ingênuas sobre os efeitos da primeira sobre a segunda, nem cobranças simplificadas daqueles que se ocupam da segunda sobre a primeira.

\section{COMO A REALIDADE SE APROPRIA DOS RESULTADOS DAS PESQUISAS}

François Dubet (2002) parte da pergunta "Porque não se acredita nos sociólogos?" para analisar as opiniões de diversos atores sociais sobre algumas conclusões de pesquisas em sociologia da educação que expressam, ora uma resistência em aceitá-las, ora uma maneira de incorporá-las parcialmente, segundo visões e interesses particulares. Ele traz alguns exemplos que lembram de perto experiências que vivemos muitas vezes quando realizamos palestras ou participamos de atividades com professores de ensino básico. Uma das questões é a suposta queda de qualidade da escola pública. Apesar dos dados históricos que a desmentem, os professores não abandonam essa crença, pois na pequena amostra de realidade na qual estão imersos, sua experiência aponta para turmas cada vez mais difíceis de ensinar. Um outro exemplo é a opinião dos professores sobre a repetência: escutar conclusões apontando que os alunos repetentes não apresentam resultados escolares melhores do que aqueles que não repetem, tendo, ao contrário, maior probabilidade de continuar a repetir ou abandonar a escola, não convence professores que já observaram alunos reprovados alcançarem um desempenho melhor no ano seguinte. Dubet explica que a escala de observação do professor é a sua classe, enquanto a perspectiva do pesquisador abrange contextos mais amplos; assim, ambos teriam razão, de acordo com os respectivos pontos de vista (p. I6)

Mas existiriam outros motivos para a não aceitação dos resultados de pesquisa, segundo o sociólogo. Seriam razões ligadas à necessidade que os atores sociais possuem de preservar o sentido de suas ações e a motivação 
de seu trabalho. No caso dos professores, que, de acordo com Durkheim, realizam um "trabalho moral", a adoção de certos valores é importante para sustentar sua ação, principalmente diante de condições difíceis e conflitivas. As análises críticas sobre o papel da escola na sociedade "são interpretadas como faltas morais individuais e convém combatê-las, reforçando o papel decisivo da virtude individual" (Dubet, 2002, p. I8). É a crença que precisa ser preservada, mesmo que isso signifique repetir as mesmas fórmulas que já não estão dando certo há algum tempo.

Dubet nota que as teorias que poderiam ser qualificadas de exógenas são geralmente mais bem aceitas do que aquelas que apontam para fatores endógenos à escola. Observa ele:

Todas as análises situando as causas das dificuldades dos alunos na sociedade e nas famílias são bem-vindas, elas reforçam a imagem da escola como santuário; todas aquelas que evocam causas localizadas no funcionamento da escola e nas práticas pedagógicas são neutralizadas. É preciso que o pecado fique fora dos muros do templo. (2002, p. 19)

Segundo ele, "os atores operam uma redução de dissonância" e selecionam as críticas que reforçam suas convicções.

Tardif e Zourhlal (2005) discutem as relações entre a pesquisa e os profissionais do ensino, com base na constatação de que a imagem da pesquisa em educação na América do Norte é bastante negativa, considerada como pouco relevante e distante das necessidades práticas dos profissionais. Buscando alcançar maior articulação entre a pesquisa e os professores, várias iniciativas foram tomadas a partir dos anos noventa em Quebec, no Canadá, como, por exemplo, integrar grupos de professores aos projetos de pesquisa. No entanto, os autores verificam que os pesquisadores continuam a conhecer mal as expectativas e representações dos professores sobre a pesquisa acadêmica. Em seu artigo, eles trazem os resultados de uma investigação que procurou cobrir algumas dessas lacunas.

O estudo entrevistou profissionais de três grupos diferentes: dirigentes de associações sindicais de professores, docentes e pesquisadores universitários e representantes do Ministério da Educação. Para colher as opiniões dos professores, foi também realizado um survey com uma amostra representativa 
de Quebec. Os resultados apontam para questões semelhantes àquelas comentadas por Dubet, constatando as mesmas queixas dos atores situados nas escolas sobre a pesquisa acadêmica e as mesmas dificuldades de comunicação entre grupos que pertencem a campos profissionais que possuem diferentes configurações e diferentes discursos sobre a educação.

No entanto, Tardif e Zourhlal apontam algumas características dos professores que estão associadas a um maior interesse e receptividade em relação aos resultados de pesquisa. Por exemplo, os professores que ganharam alguma familiaridade com a pesquisa durante sua formação inicial, que contam com mais alta escolaridade e também aqueles com maior tempo de experiência docente, estão mais abertos para conhecer a produção acadêmica sobre educação. Outro fato interessante é que os dirigentes sindicais possuem uma visão mais pessimista sobre o interesse dos professores pela pesquisa do que os dados obtidos no survey indicaram. No caso dos ocupantes de cargos técnicos no Ministério, foi constatada uma visão bastante pragmática da pesquisa, que é valorizada na medida em que fornece bases para decisões de política educacional.

Entre suas recomendações, o estudo inclui a sugestão de encontrar, na carreira do professor, um lugar para a pesquisa, pois os autores refletem que, enquanto os professores universitários são chamados a desempenhar um duplo papel em suas instituições - docência e pesquisa -, para os professores da educação básica, só o ensino conta. Eles sugerem uma diversificação da carreira docente que permita a uma parcela deles dedicar parte de seu tempo a atividades de pesquisa e difusão (Tardif, Zourhlal, 2005, p.3 I).

Dubet, em suas conclusões, reflete também sobre as ilusões da pesquisa. Um primeiro tipo de ilusão, segundo ele, seria o fato de que o pensamento crítico sobre a educação geralmente supõe que os atores se enganam sobre as funções que realmente desempenham na escola. Dessa maneira, a produção acadêmica ignora a intencionalidade desses protagonistas: segundo suas palavras "pede-se aos atores sociais para que vivam o luto de suas ações" e depois se manifesta espanto quando eles resistem a isso. Um segundo tipo de ilusão é a crença de que toda ação deriva de um projeto. Essa suposição entende que as ideias precedem a ação, quando muitas vezes a ação é que é seguida de ideias que procuram justificá-la. Dubet argumenta que os atores mudam muito mais porque mudam as regras do jogo e as condições para atuar, do que porque mudam suas ideias (p.23). 
Dubet defende a posição de que a pesquisa deve partir do pressuposto que os atores sociais possuem competências e modos de conhecimento baseados em razões, convicções e interesses. Diz ele: "a pesquisa se nutre da sociedade e de sua recepção. Nesse plano, os pesquisadores partilham de tantas ilusões quanto aqueles que eles estudam" (p.24).

Parece, então, que a linha de análise proposta por Rayou, comentada inicialmente, abre melhores possibilidades para estudar as relações entre pesquisa e realidade, focalizando a circulação de conhecimentos e opiniões entre os dois campos e não somente a influência de um sobre o outro.

\section{A CONCEPÇÃO DE "PRÁTICAS E POLÍTICAS BASEADAS EM EVIDÊNCIA"}

Há alguns anos evolui, no plano internacional, um movimento que defende que as decisões de política educacional e as práticas pedagógicas desenvolvidas nas escolas deveriam ser baseadas nas chamadas evidências produzidas por pesquisas de cunho experimental, a partir de amostras aleatórias. Essa tendência se origina do campo da medicina e vêm ganhando corpo principalmente nos Estados Unidos e no Reino Unido.

Um de seus intérpretes e divulgadores é Robert Slavin (2002), da Universidade Johns Hopkins, de Baltimore. Sua argumentação é bastante enfática e ganha, até, um tom militante, como se essa abordagem fosse salvar a educação de uma estagnação secular, causada, segundo ele, pelo fato de essa área não se ter beneficiado dos frutos da pesquisa experimental da mesma forma que outras áreas, como a agricultura, a medicina e a tecnologia em geral. Em uma conferência apresentada na reunião da Associação Americana de Pesquisa Educacional - Aera -, ele registra os sucessos desse movimento, especialmente no governo Bush, levando diversas agências governamentais a adotar um tratamento preferencial para pesquisas desse tipo, como sendo as únicas que podem dar respostas objetivas às decisões e práticas no campo da educação.

Para o autor, mesmo as pesquisas experimentais que utilizam grupos pareados em suas comparações não são confiáveis, pois elas não conseguem controlar todas as variáveis que podem estar interferindo em seus resultados ${ }^{5}$.

5. Segundo Slavin (2002, p. 17), a principal crítica aos experimentos baseados em grupos pareados é que sempre pode existir um viés na composição dos grupos que serão comparados. Por 
Slavin acredita que somente as amostras sorteadas ao acaso podem oferecer condições para resultados mais seguros que dessem aos gestores da educação uma base objetiva para suas escolhas. As reformas da educação que têm prevalecido até agora, segundo ele, são geralmente baseadas em "soluções da moda", no lugar de dados objetivos que apontem o que funciona e o que não funciona nas escolas. $\bigcirc$ autor reconhece que a utilização de amostras aleatórias é mais difícil e mais custosa, do ponto de vista financeiro, mas acredita que existem formas de superar essas dificuldades. Ele também distingue entre as decisões sobre sistemas educacionais e aquelas que são tomadas pelos professores em seu cotidiano, admitindo que nesse segundo caso, outros modelos de pesquisa podem ser úteis, a despeito dessas e de outras limitações.

Slavin defende, além disso, a realização de revisões de pesquisas por comissões independentes que possam disponibilizar suas conclusões a um público mais amplo, de forma a disseminar resultados mais consensuais sobre o que funciona bem em educação, tentando superar a tradicional resistência que haveria na área, em relação a pesquisas conduzidas com rigor. Apesar das ressalvas ao longo do texto, esse autor revela uma concepção um tanto exagerada sobre o potencial dessas pesquisas, chegando a afirmar que elas poderiam causar uma verdadeira revolução na educação (p. I 5).

Martyn Hammersley (200 I), da Open University, apresenta uma crítica sobre as chamadas "práticas baseadas em evidência" na educação. Sua crítica começa pelo exame do nome adotado - base em evidências -, segundo ele um verdadeiro slogan que, por si só, lança descrédito sobre posições diferentes. Ele argumenta que esta é uma estratégia puramente retórica, constituindo uma precária base para uma discussão racional.

A seguir, o autor examina um dos pressupostos desse movimento, que é a crença de que as práticas em educação podem ser totalmente baseadas em resultados de pesquisa, ponderando que, ao contrário, a experiência profissional é construída de uma forma muito mais complexa. Hammersley defende o ponto de vista de que existem limitações nos dois tipos de conhecimento, e que a posição de que o único conhecimento válido se origina de pesquisas empíricas não se sustenta.

exemplo, se um aluno com QI 130 é colocado em um grupo para crianças superdotadas e um outro aluno, com o mesmo QI, não é, pode acontecer que os dois sejam diferentes em relação a outras características, como motivação. 
Uma parte de sua argumentação se assenta na constatação de que as práticas profissionais em educação - assim como em outras áreas - se caracterizam por ter múltiplos objetivos, nem todos passíveis de operacionalização, sendo que a mesma ação pode gerar diferentes efeitos, alguns desejáveis e outros, não. Ele problematiza a expressão "o que funciona", mostrando que os critérios para julgar uma prática educativa nem sempre são unicamente técnicos.

Hammersley analisa a proposta da utilização de revisões de pesquisa como um instrumento para disponibilizar o conhecimento de seus resultados a um público mais amplo, incluindo gestores de políticas públicas e profissionais. Segundo ele, essas revisões não são isentas de vieses, sendo que muitas delas tendem a dar mais importância a resultados de certas pesquisas quantitativas que podem ser questionáveis, do que a pesquisas qualitativas que por vezes podem iluminar melhor aquela determinada problemática.

Trata-se, portanto, de uma concepção bastante polêmica, mas que vêm recebendo crescente destaque na literatura internacional. Na realidade, a desconfiança em relação a pesquisas acadêmicas que não são concebidas exclusivamente com finalidades práticas imediatas também se manifesta entre nós, como observamos no início do texto. A demanda por aquilo que os norte-americanos chamam de accountability, isto é, a necessidade de se prestar contas à sociedade do uso que se faz dos recursos públicos, em todas as áreas de atuação, produz um impacto na forma de avaliar a educação, reforçando a preferência por estratégias que permitam comparações e induzam a uma competição por melhores resultados, vistas como uma forma de incentivo a administradores, escolas e professores para que se tornem mais eficientes. Dentro dessa lógica, a busca por dados que fundamentem decisões a curto e médio prazo, envolvendo opções do tipo "ou isto ou aquilo", é bastante coerente com a maior confiança depositada em pesquisas experimentais como aquelas propostas por Slavin.

\section{AVANÇANDO ALGUMAS CONCLUSÕES}

Afinal, para que serve mesmo a pesquisa educacional? Vimos como a própria formulação dessa pergunta foi relativizada por vários autores citados, que preferem questionar a circulação de discursos entre a universidade e a sociedade, as relações que se dão entre os vários tipos de conhecimento e 
sobre o significado que esses conhecimentos assumem para atores sociais situados em diversos espaços profissionais.

Com efeito, a pesquisa é um tipo de atividade humana como as outras, sujeita aos mesmos constrangimentos, influências e limitações que qualquer campo de atuação. A universidade e os centros de pesquisa não estão fora da sociedade, mas, ao contrário, mantêm com ela relações diversas, mais ou menos visíveis, mas sempre contraditórias e complexas. Os conhecimentos, as teorias, as concepções, assim como versões dos resultados da pesquisa, circulam entre atores situados em diferentes setores, que rejeitam ou se apropriam deles a seu modo, devolvendo essas concepções modificadas aos pesquisadores, por meio de ações observadas, discursos colhidos e efeitos supostamente produzidos por sua atuação.

Bernardete Gatti (2006, p.29) se refere a "uma porosidade entre o que se produz nas instâncias acadêmicas e o que se passa nas gestões e ações nos sistemas de ensino", mas adverte que esses dois espaços possuem temporalidades diversas e suas interações são complexas, construídas no bojo das relações sociais concretas.

Poderíamos argumentar que é bom que seja assim, pois se é verdade que as demandas dos sistemas e do fazer pedagógico são urgentes e precisam de respostas rápidas, o pensamento crítico, a análise cuidadosa de dados empíricos e a reflexão teórica são processos que demandam condições diferentes, não só de tempo, mas de um distanciamento em relação a esse cotidiano, necessário para constituí-lo como objeto de pesquisa, recordando o alerta de Charlot.

Mais ainda, a pesquisa não é hoje somente desenvolvida na universidade, mas constitui atividade integrada ao ensino, em seus diversos níveis, ao mundo das empresas, à mídia, à propaganda, à política, entre muitas outras áreas de atividade. A atitude suposta na pesquisa, ou seja, o impulso por conhecer e conhecer dentro dos parâmetros de uma racionalidade moderna, faz parte da cultura da sociedade contemporânea.

Essa racionalidade, porém, se funde, e por vezes se choca, nas práticas cotidianas, com outros tipos de conhecimento, construídos nas experiências vividas, nas relações sociais, a partir de heranças passadas, mas também mobilizados por novos desafios em uma sociedade dinâmica, em constante mudança.

Parece, desse modo, que a pesquisa não pode fornecer respostas prontas aos sistemas de ensino. Seus resultados constituem elementos importantes a 
serem levados em conta nas decisões, mas não são os únicos e nem podem ser incorporados sem mediações. Em lugar de um confronto entre esses dois modos de conhecer e agir, seria mais interessante a possibilidade de um diálogo aberto, que nem sempre vai produzir consensos, mas que teria o potencial de contribuir para avanços, tanto na prática pedagógica como na própria pesquisa.

Nada é simples nessa construção. Por um lado, é importante lembrar que muitos dos problemas que vivemos na educação, no país, não se explicam por uma falta de conhecimento sobre o que deve ser feito, mas muito mais por uma falta de condições políticas, para viabilizar aquilo que todos sabem que deve ser feito. Por outro lado, se é verdade que os resultados de nossas pesquisas poderiam ser mais bem divulgados e mais utilizados nas decisões sobre políticas e práticas educacionais, seria ilusório imaginar que apenas esse tipo de conhecimento é mobilizado em educação. Questões mais amplas sobre valores, ética, projetos alternativos de nação, que afetam profundamente a educação, não são resolvidas com resultados de pesquisa, mas dependem de processos sociais muito mais complexos, que se inserem no bojo da história, com todos os seus conflitos e as suas contradições.

\section{REFERÊNCIAS BIBLIOGRÁFICAS}

CAILLÉ, A. Présentation. Revue du Mauss, n. 28, p. 5-40, juil./dec. 2006. (Penser la crise de l'école: perspectives anti-utilitaristes)

CAMPOS, M. M. Pesquisa em educação: algumas questões para debate. Educação \& Linguagem, v.9, n. 14, p.46-58, jul./dez. 2006.

CASTRO, M. H Entrevista. Veja, n.2.047, 13 fev. 2008. Disponível em: http://veja.abril.com. br//30208/entrevista.shtml. Acesso em: set. 2008.

CHARLOT, B. A Pesquisa educacional entre conhecimentos, políticas e práticas: especificidades e desafios de uma área de saber. Revista Brasileira de Educação, v. I I, n.31 , p.7- |8, jan./abr. 2006.

DUBET, F. Pourquoi ne croit-on pas les sociologues? Éducation et Sociétés, n.9, p. 13-25, 2002.

GATTI, B. A. A Pesquisa na pós-graduação e seus impactos na educação. Educação \& Linguagem, v.9, n. 14, p. 16-33, jul./dez. 2006.

HAMMERSLEY, M. Some questions about evidence-based practice in Education. In : CONFERENCIAANUAL DA ASSOCIAÇÃO BRITANICA DE PESQUISA EDUCACIONAL. Anais... 
Leeds (U. K.), University of Leeds, set. 200 I . Disponível em: http://www.leeds.ac.uk/educol/ documents/0000 I819.doc. Acessado em: I3 jun. 2008.

RAYOU, P. Présentation. Éducation et Sociétés, n.9, p.5-II , 2002. (Dossier. À quoi sert la sociologie de l'éducation? ou: La circulation des savoirs entre sociologie de l'éducation et société)

SLAVIN, R. E. Evidence-based education policies: transforming educational practice and research. Educational Researcher, v.31, n.7, p. 15-21, out. 2002.

TARDIF, M.; ZOURHAL, A. Difusão da pesquisa educacional entre profissionais do ensino e círculos acadêmicos. Cadernos de Pesquisa, v.35, n. 125, p. I3-35, maio/ago. 2005.

Recebido em: setembro 2008

Aprovado para publicação em: dezembro 2008 